\title{
Determinants of Early Days of Newborn Feeding Malpractice Among Mothers of Children Less Than One Year of Age in Mizan-Aman Town, Southwestern Ethiopia, 2020
}

This article was published in the following Dove Press journal:

Pediatric Health, Medicine and Therapeutics

\section{Muluken Amare Wudu}

Department of Pediatrics and Child Health Nursing, College of Medicine and Health Sciences, Wollo University, Dessie, II45, Ethiopia
Correspondence: Muluken Amare Wudu Department of Pediatrics and Child Health Nursing, College of Medicine and Health Sciences, Wollo University, P. O. Box: I | 45, Dessie, Ethiopia Tel +25 I 912975922

$\mathrm{Fax}+251333115052$

Email 385mule@gmail.com
Background: Suboptimal breastfeeding practices have remained a global public health issue, particularly in Ethiopia due to early days of newborn breastfeeding practices. Although several measures have been taken to comply with the WHO guidelines, newborn feeding malpractices are widely seen in Ethiopia.

Objective: To assess the prevalence and determinant of early days of newborn feeding malpractices among recently delivered women in Mizan-Aman Town, southwestern Ethiopia, 2020.

Methods: A community-based cross-sectional study of recently delivered women was conducted between March 5/2020 and April 8/2020. A total of 487 mother-to-child $(<12$ month) pairs were selected using a multi-stage randomized sampling technique and the data were collected through a face-to-face interview using a structured questionnaire. The result was analyzed via SPSS version 26. Multivariate logistic regression analysis was used to assess the determinant of newborn feeding malpractices and a $\mathrm{p}<0.05$ was deemed to be significant.

Results: Prevalence of prelacteal feeding, delayed initiation of breastfeeding and colostrum avoidance was approximately $21.9 \%, 35.5 \%$ and $15.5 \%$, respectively. The most common prelacteal food was Rue/“Tenadam”/49 (10.1\%). The key reasons for this were: 49 (10.1\%) Cultural activity followed by $45(9.3 \%)$ intestinal/ghost/birth clean-ups. Determinants of prelacteal feeding were found to be: mothers who recognize the risks of prelactate feeding, multipara mothers, had $\geq 4$ children and infants birth order between 4 and 6 . Likewise, exposure to infant formula advertising, absence of home-to-home health education, multipara mothers and spontaneous vaginal birth were the determinants of colostrum avoidance.

Conclusion: The study found that one in four and one-third of newborns had experience with prelacteal and delayed breastfeeding, respectively. This makes the newborn feeding practice suboptimal in the city. As a result, behavioral modification programs on the prevention of prelacteal feeding and enhancement of early initiation of colostrum feeding practices are recommended.

Keywords: suboptimal breastfeeding, prelacteal feeding, colostrum avoidance

\section{Introduction}

Breast milk is a fundamental right, nutritious, has an optimum temperature, does not require any preparation and is easily accessible to infant food. ${ }^{1}$ Colostrum is the first milk, yellowish in color, thick and produced just 3-4 days after birth. It 
provides all the essential nutrients for baby growth and well-being, immune factors and helps the newborn to get through meconium. As such, colostrum is considered to be the first and infant immunization. ${ }^{2}$

Exercising optimal breastfeeding benefits both infants and mothers. It protects the infant from acquiring infectious morbidity and mortality, overweight, diabetes and chronic disease as well as can prevent mothers breast cancer, better birth spacing, reduce the risk of diabetes and ovarian cancer. Therefore, making the breastfeeding practice to universal level, could save about 823,000 child death and 20,000 breast cancer death every year. ${ }^{3}$

Despite the recommendation of the World Health Organization (WHO) that early initiation of colostrum feeding and exclusive breastfeeding as a golden standard for early infant feeding, about 78 million newborns worldwide waited for more than one hour to breastfeed, two out of five newborns were given fluids or solids other than breast milk and excluded from colostrum feeding in the early days of their life. ${ }^{1,4}$

Globally, neonatal death has remained the lion share of (45\%) among all under-five deaths in $2018 .^{5}$ Similarly, every day, about 4000 infants and young children die due to Colostrum avoidance and introduction of prelacteal feds, worldwide. ${ }^{6}$ As a result, many infants suffer from insufficient breast milk, lactation failure and insufficient weight gain. Likewise, $45 \%$ of neonatal infectious deaths, $30 \%$ of diarrheal deaths and $18 \%$ of acute respiratory deaths among under five children associated with inappropriate feeding practices. ${ }^{7-9}$

While Ethiopia has a strong experience in early initiation of colostrum feeding (73.3\%), it does not always comply with WHO/UNICEF recommendations. ${ }^{4}$ At the national level, one in four infants $(25.29 \%)$ received prelacteal feed during the first three days of life ${ }^{10}$ and colostrum avoidance practices ranged from $6.3 \%$ up to $67.2 \%$ in Tigray Aksum and Meshenti, northwest Ethiopia. ${ }^{11,12}$ As a result, $18 \%$ of infant deaths could be due to suboptimal breastfeeding practices. ${ }^{13}$

Studies conducted in Ethiopia have shown that there are multifactorial determinants of early newborn feeding malpractices such as: socio-demographic factors, place and mode of delivery, low level of breastfeeding information, lack of postnatal care and breastfeeding advice. ${ }^{10,11,14,15}$

Since 2004, Ethiopia has adapted the Guideline for Infant and Young Child Feeding Practices (IYCF) ${ }^{16}$ and the 2013 National Nutrition Policy to promote optimal breastfeeding practices through multi-sectoral integration. ${ }^{17}$
While remarkable advances have been made with regard to the optimal promotion of breastfeeding at the facility and at the community extent the level of current practice is not well documented in the study area. In addition, previous studies were merely institution-based, outdated studies, and did not compile a delayed initiation of breastfeeding, prelacteal feeding, and colostrum avoidance report in one as well. Therefore, this study was initiated in order to assess the magnitude and determinants of prelacteal feeding among recently delivered mothers in Mizan-Aman Town, southwestern Ethiopia. This helps to fill the information gap and to provide possible recommendations for health managers, professionals, and other stakeholders working in maternal and child health institutions.

\section{Methods and Materials}

\section{Study Area and Period}

The study was conducted between March 3 and April 3, 2020, in the town of Mizan-Aman, the capital of the Bench Sheko zone. The town is located $561 \mathrm{~km}$ from Addis Ababa, administratively structured by five kebeles and has a total population of 49,590 , of which 11,554 are women in the 15-49 age group and 1582 are children under the age of one. Cash crop farming and gold mining are the key economic activity in the city. It has one teaching hospital, one public health center, 10 private health institutions and 17 drug stores.

\section{Study Design}

A community-based cross-sectional study was employed.

\section{Source of Population}

All mothers of infants less than one year of age that are living in Mizan-Aman town.

\section{Study Population}

A randomly selected Mothers of infant less than one year of age that are living in Mizan-Aman town during data collection period was considered as study population.

\section{Eligibility Criteria}

Mothers of infants less than one year of age who are permanent residents of Mizan-Aman town and willing to take part in the study were involved. Those who get serious medical illness, mental problems or unwilling to participate in this study were excluded. 


\section{Sample Size and Sampling Procedures}

The sample size was determined using a single population proportion formula, assuming a 50\%, 95\% CI, 5\% marginal error prevalence for prelacteal feeding. Correction formula was used since the source of population was $<10,000$, and the sample was multiplied by a design effect of 1.5 and finally, the final sample size was 487 by adding $5 \%$ non-response rate.

Multi-stage randomized sampling technique was used. The town of Mizan-Aman has two sub-city and five kebeles. The sub-city of Mizan has 3 kebeles and the subcity of Aman has 2 kebeles. Of these, a total of 3 kebeles were selected using the lottery process. In order to achieve the sample size of each of the 3 kebeles, a proportional allocation to the size was made following the sampling fraction/interval, the mother-child pair was selected on a three-house basis using a systematic random sampling by reference to the Community Health worker family record book as a sampling frame.

\section{Operational Definition}

Prelacteal feeding; is defined as giving fluid or semisolid before breastfeeding to the infant within the first three days after birth. ${ }^{18}$

Delayed initiation of breastfeeding; breastfeeding initiates beyond the first hour of the life of the newborn. ${ }^{18}$

Colostrum avoidance; includes; pumping and discarding of colostrum during the first five days after birth. ${ }^{18}$

Those women who practiced prelacteal feeding or delayed initiation of breastfeeding or colostrum avoidance in the early days of newborn were deemed "early days of newborn feeding malpractice". ${ }^{18}$

\section{Data Collection}

The tool was adapted from the 2016 Ethiopian Demographic and Health Survey (EDHS) document ${ }^{18}$ and structured questionnaires were used to collect data through face-to-face interviews. The questionnaire was first prepared in English and translated into Amharic language. Data quality was ensured by recruiting $5 \mathrm{BSc}$ nurses as data collectors, providing training for data collectors and performing pre-tests in $5 \%$ of the sample size of the mother-to-child pair in the Debrework town.

\section{Data Analysis}

The data were cleaned, encoded and entered into Epi Info version 3.5.3 and exported to SPSS version 25 of the statistical package for analysis. Descriptive statistics were computed to determine the magnitude of the suboptimal breastfeeding practice. In addition, a bivariate logistic regression technique was used. Subsequently, these variables with $\mathrm{p}<0.2$ were moved to a multivariate analysis and evaluated using a stepwise multivariate logistic regression technique to monitor the effects of confounding and to classify predictors of suboptimal breastfeeding practices. A P-value of $<0.05$ was found to be statistically significant at a $95 \%$ confidence interval.

\section{Result}

\section{Socio-Demographic Characteristics of} the Respondents

A total of 487 mother-to-child pairs were included in the study, resulting in a response rate of 485 (99.6\%). The majority of women, $184(37.9 \%)$, were 20-24 years of age and the mean $( \pm$ SD) age of mothers was $24.5( \pm 5.5)$ years of age. In addition, of the total respondents, 459 (94.6\%) were married, $291(60 \%)$ had a family size $\geq 4$, $284(58.6 \% \mathrm{t})$ were housewives by occupation, and 167 (34.4\%) attended primary school. Moreover, about 229 $(47.2 \%)$ of infants were first-order/first-child for their families. The majority of the husbands, 188 (38.8\%), had secondary education, 238 (49.1\%) were government employees by occupation, and 270 (55.7\%) had $>1500$ Birr monthly income (Table 1).

\section{Obstetrics and Maternal Health Service Utilization}

The majority of mothers were multiparous, 249 (51.3\%), 470 (96.9\%) of women attended ANC, 315 (67\%) of them used ANC four and more times, while at the ANC clinic, $280(59.6 \%)$ of them had received breastfeeding counseling. In addition, $434(89.5 \%)$ of the study participants delivered their child at public health facility and were assisted by skilled birth attendants and delivered 435 (89.7\%) by usual spontaneous delivery (Table 2 ).

\section{Breastfeeding Practice}

While all mothers have breastfed their current babies, 172 (35.5\%) of newborns were given breastfeeding after one hour (Figure 1). In addition, 75 (15.5\%) of women were discarded colostrum for their infants within the first five days after birth. The key reasons for refusing colostrum were: 50 (10.3\%) breastfeeding problems, 19 (3.9\%) maternal medical illness and 6(1.23\%) infant health reasons (Table 3). 
Table I Socio-Demographic Characteristics of Mothers of Children Aged Less Than One Year in Mizan-Aman Town, Southwestern Ethiopia, 2020 ( $N=485)$

\begin{tabular}{|c|c|c|}
\hline $\begin{array}{l}\text { Socio-Demographic } \\
\text { Variables }\end{array}$ & $\begin{array}{l}\text { Frequency } \\
(\mathrm{N}=485)\end{array}$ & $\begin{array}{l}\text { Percentage } \\
\text { (\%) }\end{array}$ \\
\hline \multicolumn{3}{|l|}{ Family size } \\
\hline$\leq 3$ & 194 & 40.0 \\
\hline$>4$ & 291 & 60.0 \\
\hline \multicolumn{3}{|l|}{ Age of mothers } \\
\hline $15-19$ years & 51 & 10.5 \\
\hline 20-24 years & 184 & 37.9 \\
\hline $25-29$ years & 162 & 33.4 \\
\hline$>30$ years & 88 & 18.1 \\
\hline \multicolumn{3}{|l|}{ Maternal marital status } \\
\hline Single & 20 & 4.1 \\
\hline Married & 459 & 94.6 \\
\hline Other & 6 & 1.2 \\
\hline \multicolumn{3}{|l|}{$\begin{array}{l}\text { Maternal educational } \\
\text { level }\end{array}$} \\
\hline Informal education & 142 & 29.3 \\
\hline Primary education & 167 & 34.4 \\
\hline $\begin{array}{l}\text { Secondary education and } \\
\text { above }\end{array}$ & 176 & 36.2 \\
\hline \multicolumn{3}{|l|}{ Maternal religion } \\
\hline Orthodox & 192 & 39.6 \\
\hline Protestant & 179 & 36.9 \\
\hline Muslim & 114 & 23.5 \\
\hline \multicolumn{3}{|l|}{ Maternal occupation } \\
\hline Government employee & 58 & 12.0 \\
\hline House wife & 284 & 58.6 \\
\hline Others & 143 & 29.4 \\
\hline \multicolumn{3}{|l|}{ Birth order of the infant } \\
\hline First & 229 & 47.2 \\
\hline$\geq 2$ & 256 & 52.7 \\
\hline \multicolumn{3}{|l|}{$\begin{array}{l}\text { No_of children in the } \\
\text { family }\end{array}$} \\
\hline$\leq 3$ & 424 & 87.4 \\
\hline$\geq 4$ & 61 & 12.6 \\
\hline \multicolumn{3}{|l|}{$\begin{array}{l}\text { Husband educational } \\
\text { status }\end{array}$} \\
\hline Unable to read and write & 14 & 2.9 \\
\hline Able to read and write & 29 & 6 \\
\hline Primary education & 98 & 20.2 \\
\hline Secondary education & 188 & 38.8 \\
\hline Higher education & 156 & 32.1 \\
\hline \multicolumn{3}{|l|}{ Husband occupation } \\
\hline Private work & 203 & 41.9 \\
\hline Gov't work & 238 & 49.1 \\
\hline
\end{tabular}

(Continued)
Table I (Continued).

\begin{tabular}{|c|l|l|}
\hline $\begin{array}{l}\text { Socio-Demographic } \\
\text { Variables }\end{array}$ & $\begin{array}{l}\text { Frequency } \\
\mathbf{( N = 4 8 5 )}\end{array}$ & $\begin{array}{l}\text { Percentage } \\
\text { (\%) }\end{array}$ \\
\hline Farmer & 38 & 7.8 \\
Other & 6 & 1.2 \\
\hline Husband monthly income & & \\
$<500$ Birr & 25 & 5.1 \\
$500-1000$ Birr & 108 & 22.3 \\
I00I-1500 Birr & 82 & 16.9 \\
$>1500$ Birr & 270 & 55.7 \\
\hline Infant sex & & \\
Male & 209 & 43.1 \\
Female & 276 & 56.9 \\
\hline
\end{tabular}

Table 2 Health Service Utilization Among Mothers of Children Less Than One Year of Age in Mizan-Aman Town, Southwestern Ethiopia, $2020(\mathrm{~N}=485)$

\begin{tabular}{|c|c|c|}
\hline Variables & $\begin{array}{l}\text { Frequency } \\
(\mathrm{N}=485)\end{array}$ & $\begin{array}{l}\text { Percentage } \\
\text { (\%) }\end{array}$ \\
\hline \multicolumn{3}{|l|}{ Attending antenatal care $(n=485)$} \\
\hline Yes & 470 & 96.9 \\
\hline No & 15 & 3.1 \\
\hline \multicolumn{3}{|l|}{$\begin{array}{l}\text { Frequency of antenatal care } \\
(n=470)\end{array}$} \\
\hline I time & 11 & 2.3 \\
\hline $2-3$ times & 144 & 30.6 \\
\hline$\geq 4$ & 315 & 67.0 \\
\hline \multirow{2}{*}{\multicolumn{3}{|c|}{$\begin{array}{l}\text { Get breastfeeding counseling at } \\
\text { ANC clinic }(n=470)\end{array}$}} \\
\hline & & \\
\hline Yes & 280 & 59.6 \\
\hline No & 190 & 40.4 \\
\hline \multicolumn{3}{|l|}{ Place of delivery $(n=485)$} \\
\hline Gov't health facility & 434 & 89.5 \\
\hline Private clinic & 2 & 0.4 \\
\hline At home & 48 & 9.9 \\
\hline TBAs place & I & 0.2 \\
\hline \multicolumn{3}{|l|}{ Mode of delivery $(n=485)$} \\
\hline CS delivery & 49 & 10.1 \\
\hline Normal spontaneous delivery & 435 & 89.7 \\
\hline Instrumental delivery & I & 0.2 \\
\hline \multicolumn{3}{|l|}{ Delivery attendant $(n=485)$} \\
\hline Health professionals & 435 & 89.7 \\
\hline Traditional birth attendants & 50 & 10.3 \\
\hline
\end{tabular}

\section{Prelacteal Feeding Practice}

Of the total respondents, within the first three days after birth, $106(21.9 \%)$ were given prelacteal feed other than 


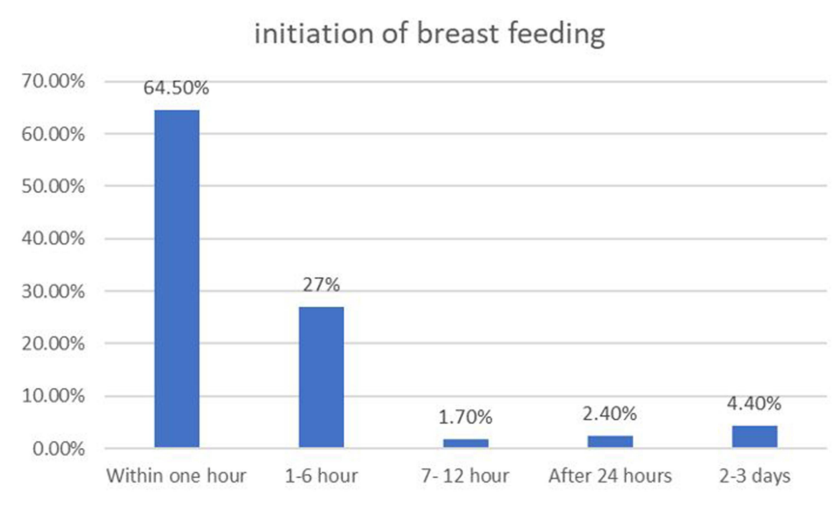

Figure I Initiation of breastfeeding among mothers of children less than one year of age in Mizan-Aman town, Southwestern Ethiopia, 2020 ( $N=485)$.

breastfeed for their babies. Water with "Tenadam"/rue 49 (10.1\%), followed by plain water $33(6.8 \%)$, glucose with water $10(2.1 \%)$ and formula milk 9(1.9\%) were the most popular types of prelacteal food. The main reasons for prelacteal feeding were: $49(10.1 \%)$ cultural practice, $45(9.3 \%)$ intestinal/throat/mouth cleanse, 31 (6.4\%) due to breastfeeding problems, and 19 (3.9\%) of mothers believed that newborn breastfeeding would be thirsty (Table 4).

As for guidance on offering this form of prelacteal feeding; their own decision was a dominant factor, 51 (10.5\%), followed by grandparents; 28 (5.8\%), their friends; $15(3.1 \%)$, most recently health professionals; 8 (1.6\%) (Figure 2).

Table 3 Colostrum Avoidance Among Mothers of Children Less Than One Year of Age in Mizan-Aman Town, Southwestern Ethiopia, $2020(\mathrm{~N}=485)$

\begin{tabular}{|l|l|l|}
\hline Variables & $\begin{array}{l}\text { Frequency } \\
(\mathbf{N}=485)\end{array}$ & Percent \\
\hline $\begin{array}{l}\text { Breastfed ever their current } \\
\text { infant } \\
\text { Yes }\end{array}$ & 485 & 100 \\
\hline $\begin{array}{l}\text { Initiation of breastfeeding } \\
<\text { I hour } \\
>\text { I hour }\end{array}$ & 296 & 64.5 \\
\hline $\begin{array}{l}\text { Colostrum avoidance } \\
\text { Yes }\end{array}$ & 163 & 35.5 \\
\hline No & 75 & 15.5 \\
\hline $\begin{array}{l}\text { Reason for colostrum } \\
\text { avoidance } \\
\text { Breastfeeding problem } \\
\text { Maternal medical illness }\end{array}$ & 410 & 84.5 \\
\hline \begin{tabular}{l} 
For baby's health \\
\hline
\end{tabular} & 19 & 10.3 \\
\hline
\end{tabular}

Table 4 Prelacteal Feeding Among Mothers of Children Less Than One Year of Age in Mizan-Aman Town, Southwestern Ethiopia, $2020(\mathrm{~N}=485)$

\begin{tabular}{|l|l|l|}
\hline Variables & Frequency & Percent \\
\hline $\begin{array}{l}\text { Prelacteal feeding } \\
\text { Yes }\end{array}$ & 106 & 21.9 \\
No & 379 & 78.1 \\
\hline Type of prelacteal food & & \\
Water and Tenadam/rue & 49 & 10.1 \\
Plain water & 33 & 6.8 \\
Sugar with water & 10 & 2.1 \\
Formula milk & 9 & 1.9 \\
Butter & 5 & 1 \\
\hline Reasons for prelacteal feeding were & & \\
Cultural practice & 49 & 10.1 \\
To clean infants' bowel/throat/mouth & 45 & 9.3 \\
Breastfeeding problem & 31 & 6.4 \\
Mothers believed that breastfeed for & 19 & 3.9 \\
new born will be thirsty & & \\
For infant health & 14 & 2.9 \\
Maternal medical illness & 11 & 2.3 \\
To calm/soothe the baby & 9 & 1.9 \\
\hline
\end{tabular}

\section{Factor Associated with Prelacteal Feeding}

The bivariate logistic regression analysis showed that mothers in age groups between 20-24 years and 35-39 years, mothers in income $>1500$ Birr/month, infants birth order between 4 and 6, multipara mothers, mothers assisted by traditional birth attendants and mothers who knew the risk of pre-lacteal feeding were statistically significant ( $\mathrm{p}$-value $<0.05$ ) with pre-lacteal feeding. In addition, the variables with $\mathrm{p}<0.2$ from the bivariate analysis were shifted and analyzed by multivariate logistic regression analysis.

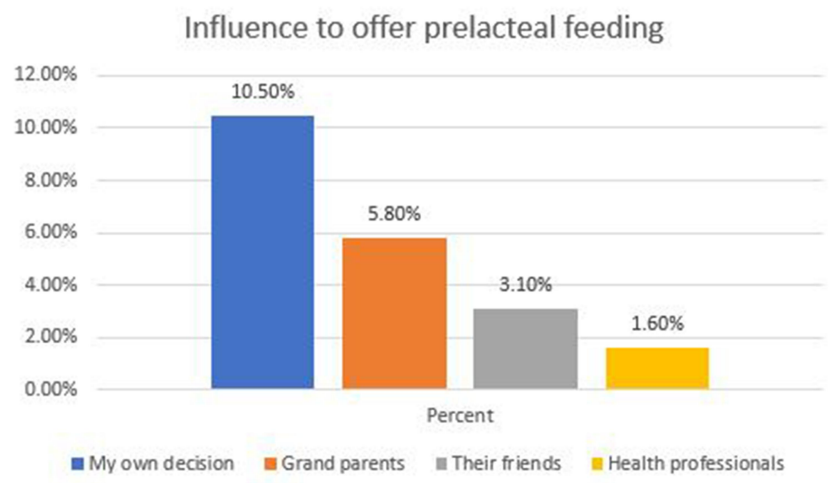

Figure 2 Influence/advice to provide prelacteal feeding among mothers of children less than one year of age in Mizan-Aman town, Southwestern Ethiopia, 2020 $(\mathrm{N}=485)$. 
In multivariate logistic regression analysis; multipara mothers, infants born in order $4-6$, having $\geq 4$ children, and mothers who recognized the risk of prelacteal feeding were determinants of prelacteal feeding. Multipara mothers were nearly four times $(\mathrm{AOR}=3.56 ; 95 \% \mathrm{CI}=$ 1.036-12.227) times more likely to give prelacteal feed than their counterparts. The odds of prelacteal feeding among mothers who knew the risk of prelacteal feeding were almost seven times $\quad(\mathrm{AOR}=6.91 ; 95 \%$ $\mathrm{CI}=3.002-15.904)$, higher than the counterpart. Furthermore, infant's birth order between 4 and 6 were twelve $(\mathrm{AOR}=12.28 ; 95 \% \mathrm{CI}=1.528-18.639)$ times more likely to give prelacteal feeding when compared to infant's birth order one. The odds of prelacteal feeding among mothers with $\geq 4$ number of children were nearly five times $(\mathrm{AOR}=5.2 ; 95 \% \mathrm{CI}=1.033-12.141)$, higher than, those mothers with $\leq 3$ number of children (Table 5).

\section{Factors Associated with Colostrum Avoidance}

In bivariate logistic regression, the following were: mothers aged between 20-24 years and 25-29 years, infant birth order between 2 and 3 years, having $\geq 4$ children, multipara mothers, spontaneous vaginal delivery, having exposure to infant formula advertising and not having home health education statistically significant with colostrum avoidance.

In multivariate logistic regression analysis; exposure to infant formula advertisement, lack of home health education, being multipara mothers and delivered through spontaneous vaginal delivery were determinants of colostrum avoidance. The odds of colostrum avoidance among mothers who have exposure to infant formula advertisement were nearly seven times $(\mathrm{AOR}=7.476 ; 95 \% \mathrm{CI}=$ 3.549-15.752), higher than the counterpart. Likewise, the odds of colostrum avoidance among mothers who do not have home to home health education were nearly five times, $(\mathrm{AOR}=5.474 ; 95 \% \mathrm{CI}=2.876-10.419)$, higher than their counterparts. Moreover, multipara mothers were ten $(\mathrm{AOR}=10.045 ; 95 \% \mathrm{CI}=1.456-19.289)$ times more likely to practice colostrum avoidance when compared to primipara mothers. The odds of colostrum avoidance among mothers who gave birth via spontaneous vaginal delivery were three times $(\mathrm{AOR}=3.106 ; 95 \%$ $\mathrm{CI}=1.245-7.750$ ), higher than, those mothers who gave birth through CS (Table 6).

\section{Discussion}

This study found that early newborn feeding practices were suboptimal in the setting of the study due to the widespread implementation of prelacteal feds, delayed initiation of breastfeeding and colostrum prevention. The prelacteal feeding, delayed initiation of breastfeeding and colostrum-avoidance prevalence were found to be $21.9 \%$, $35.5 \%$ and $15.5 \%$, respectively, in Mizan-Aman-town.

Prevalence of prelacteal feeding in this study was relatively comparable with studies in Wolayta sodo (20.6\%), Tigray (24.7\%) and Dabat district (26.8\%). ${ }^{15,19,20}$ However, my results are far higher than those found in other studies in Sidama (5.5\%), Mettu (14.2\%) and Debrebirhan (14.2\%). ${ }^{21-23}$ The observed difference could be due to differences in culture of access to health care and population characteristics. However, the results in this study are much lower than those found in other studies in South Sudan (53\%), Vietnam (73.3\%), Egypt (58\%), Amhara (47.2\%) and the Harare region (43.5\%) in Ethiopia. ${ }^{18,24-27}$ This may be due to religious and cultural practices that have a lion's share in the provision of prelacteal food in the regions mentioned above, most of which have been in rural areas. In addition, the role of grandparents in early newborn care is vital in the extended family culture, particularly in Ethiopia.

In this study, the magnitude of colostrum-avoidance was consistent with studies in Raya Kobo district (13.5\%), Tigray district (15\%) and Mettu, southwestern Ethiopia (17.5\%). ${ }^{19,22,28}$ However, colostrum avoidance practices are higher in Mizan-Aman than in Aksum City (6.3\%), Wolayta Sodo (8.5\%) and Kombolicha City (11.4\%) in Ethiopia. ${ }^{11,15,29}$ This distinction may be attributed to the use of socio-cultural, maternal health service and the number of institutional deliveries. The findings I have obtained are far smaller than those seen in other studies in Dabat, Northwest Ethiopia (47.1\%), Debrebirhan, central Ethiopia (20.3\%) and South Sudan $(38.8 \%){ }^{20,23,24}$ This disparity may be due to socio-cultural differences and they felt that colostrum would cause their babies to have abdominal crap and have bad sprit and should be discarded.

This study showed that those mothers who recognized the risk of prelacteal feeding were almost seven times (AOR=6.91; 95\% CI= 3.002-15.904), higher than their counterparts. The report is contrary to studies carried out in the district of Mettu, Sidama and Raya Kobo. ${ }^{22,24,28}$ The disparity may be due to the fact that while mothers have 
Table 5 Factors Associated with Prelacteal Feeding Practices Among Mothers of Children Aged Less Than I2month in Mizan-Aman Town, Southwestern Ethiopia, 2020

\begin{tabular}{|c|c|c|c|c|}
\hline \multirow[t]{2}{*}{ Variables } & \multicolumn{2}{|c|}{ Prelacteal Feeding } & \multirow[t]{2}{*}{ COR (Cl: 95\%) } & \multirow[t]{2}{*}{ AOR (Cl: 95\%) } \\
\hline & Yes (\%) & No (\%) & & \\
\hline \multicolumn{5}{|l|}{ Age of respondents } \\
\hline $15-19$ & $21(41.2 \%)$ & $30(58.8 \%)$ & 1 & I \\
\hline $20-24$ & $40(21.7 \%)$ & $144(78.3 \%)$ & $2.52(1.304-4.869)^{*}$ & $0.626(0.174-2.26)$ \\
\hline $25-29$ & $26(16 \%)$ & $136(84 \%)$ & $3.66(1.82-7.357)$ & $0.983(0.237-4.07 I)$ \\
\hline $30-34$ & $13(25.5 \%)$ & $38(74.5 \%)$ & $2.046(0.882-4.745)$ & $0.208(0.032-1.35 I)$ \\
\hline $35-39$ & $6(19.4 \%)$ & $25(80.6 \%)$ & $2.917(1.019-8.344)^{*}$ & $0.856(0.08-9.125)$ \\
\hline \multicolumn{5}{|l|}{ Income } \\
\hline$<500 \mathrm{~B} /$ month & $77(24.3 \%)$ & $240(75.7 \%)$ & 1 & I \\
\hline $500-1000 \mathrm{Br} /$ month & $18(22.5 \%)$ & $62(77.5 \%)$ & $1.105(0.616-1.982)$ & $0.677(0.223-2.06 \mathrm{I})$ \\
\hline $1001-1500 \mathrm{Br} /$ month & $5(26.3 \%)$ & I4(73.7\%) & $0.898(0.313-2.575)$ & $0.25(0.045-1.39)$ \\
\hline$>1500 \mathrm{Br} /$ month & $6(8.7 \%)$ & $63(91.3 \%)$ & $3.369(1.403-8.088)^{*}$ & $1.224(0.321-4.678)$ \\
\hline \multicolumn{5}{|l|}{ Birth order of infant } \\
\hline Birth order I & $58(25.3 \%)$ & $17 \mid(74.7 \%)$ & 1 & I \\
\hline Birth order $2-3$ & $4 I(20.8 \%)$ & $156(79.2 \%)$ & $1.291(0.819-2.034)$ & $2.568(0.696-9.473)$ \\
\hline Birth order 4-6 & $5(9.8 \%)$ & $46(90.2 \%)$ & $3.12(1.183-8.23)^{*}$ & $12.276(1.528-18.639)^{* *}$ \\
\hline \multicolumn{5}{|l|}{ NO_ of children } \\
\hline$\leq 3$ & $98(23.1 \%)$ & $326(76.9 \%)$ & I & 1 \\
\hline$\geq 4$ & $8(13.1 \%)$ & $53(86.9 \%)$ & $1.992(0.916-4.331)$ & $5.197(1.033-12.141)^{* *}$ \\
\hline \multicolumn{5}{|l|}{ Parity } \\
\hline Primipara & $61(25.8 \%)$ & $175(74.2 \%)$ & I & 1 \\
\hline Multipara & $45(18.1 \%)$ & $204(81.9 \%)$ & $1.58(I .023-2.44 I)^{*}$ & $3.558(1.036-12.227)^{* *}$ \\
\hline \multicolumn{5}{|l|}{ Delivery attendant } \\
\hline Health professional & $87(20 \%)$ & $348(80 \%)$ & 1 & 1 \\
\hline Traditional birth attendant & $19(38 \%)$ & $31(62 \%)$ & $2.452(1.322-4.546)^{*}$ & $1.668(0.436-6.379)$ \\
\hline \multicolumn{5}{|l|}{ Mother knows demerits of PLF } \\
\hline Yes & $17(5.7 \%)$ & $280(94.3 \%)$ & $14.807(8.398-26.108)^{*}$ & $6.909(3.002-15.904)^{* *}$ \\
\hline No & $89(47.3 \%)$ & $99(52.7 \%)$ & 1 & $\mathrm{I}$ \\
\hline
\end{tabular}

Notes: *Stands for statistically significant at $p<0.05$ in bivariate analysis and **stands for statistically significant at $p<0.05$ in multivariate analysis.

recognized the risk of prelacteal feeding, they may experience medical illness, CS delivery and problems with breastfeeding, in particular the lack of milk secretions during the first three days of birth. Because of this, they might be worried about the survival of their child for this cause. This, on the other hand, leads to the offering of prelacteal feds to their infant. The other possible justification may be that, even though mothers have obtained ample information from health facilities, community health workers and mass media about breastfeeding, the power of local community members, particularly grandparents, may lead them to give prelacteal feeding. This implies that improving the quality of newborn care service and avoiding cultural feeding malpractices at the community level would substantially avoid suboptimal breastfeeding practices.

This study showed that infant's birth order between 4 and 6 were twelve $(\mathrm{AOR}=12.28 ; 95 \% \mathrm{CI}=1.528-18.639)$ times more likely to give prelacteal feeding when compared to infant's birth order one. The odds of prelacteal feeding among mothers having $\geq 4$ number of children were nearly five times (AOR $=5.2 ; 95 \% \mathrm{CI} ; 1.033-12.141$ ), higher than, those mothers having $\leq 3$ number of children. This is consistent with study from Harare Region, Eastern Ethiopia. ${ }^{27}$ The finding, however, contradicts the Nepal report, which was the first order of infant births. ${ }^{30}$ This could be due to the gap in; mothers of infants whose births order 4-6 and mothers who have $\geq 4$ number of children 
Table 6 Factors Associated with Colostrum Avoidance Practices Among Mothers of Children Aged Less Than 12month in MizanAman Town, Southwestern Ethiopia, 2020

\begin{tabular}{|c|c|c|c|c|}
\hline \multirow[t]{2}{*}{ Variables } & \multicolumn{2}{|c|}{ Colostrum Avoidance } & \multirow{2}{*}{ Crude OR (Cl: 95\%) } & \multirow[t]{2}{*}{ Adjusted OR (Cl: 95\%) } \\
\hline & Yes (\%) & No (\%) & & \\
\hline \multicolumn{5}{|l|}{ Age of respondents } \\
\hline $15-19$ years & $16(21.3 \%)$ & $35(8.5 \%)$ & 1 & I \\
\hline 20-24 years & $25(33.3 \%)$ & $159(38.8 \%)$ & $2.97(1.406-6.012)^{*}$ & I.447(0.584-3.58I) \\
\hline $25-29$ years & $20(26.7 \%)$ & $142(34.6 \%)$ & $3.246(1.527-6.901)^{*}$ & $1.210(0.436-3.363)$ \\
\hline $30-34$ years & $\mathrm{II}(14.7 \%)$ & $40(9.8 \%)$ & I.662(0.68I-4.055) & $0.163(0.039-0.67 I)$ \\
\hline $35-39$ years & $3(4 \%)$ & $28(6.8 \%)$ & $4.267(1.1 .29-16.124)^{*}$ & $0.229(0.035-1.495)$ \\
\hline \multicolumn{5}{|l|}{ Infant birth order } \\
\hline Infant birth order I & $43(57.3 \%)$ & $186(45.4 \%)$ & I & I \\
\hline Infant birth order 2-3 & $31(41.3 \%)$ & $166(40.5 \%)$ & $1.238(0.746-2.055)$ & $0.21 \mathrm{I}(0.032-1.385)$ \\
\hline Infant birth order 4-6 & $\mathrm{I}(\mathrm{I} .3 \%)$ & $50(12.2 \%)$ & II.559(I.553-16.016)* & $4.375(0.235-19.927)$ \\
\hline \multicolumn{5}{|l|}{ NO_of children } \\
\hline$\leq 3$ & $74(98.7 \%)$ & $350(85.4 \%)$ & 1 & 1 \\
\hline$\geq 4$ & $\mathrm{I}(\mathrm{I} .3 \%)$ & $60(14.6 \%)$ & $12.688(1.730-32.996)^{*}$ & $4.335(0.052-16.505)$ \\
\hline \multicolumn{5}{|l|}{ Parity } \\
\hline Primipara & $46(61.3 \%)$ & $190(46.3 \%)$ & I & I \\
\hline Multipara & $29(38.7 \%)$ & $220(53.7 \%)$ & I.837(1.II-3.039)* & $10.045(1.456-19.289)^{* *}$ \\
\hline \multicolumn{5}{|l|}{ Mode of delivery } \\
\hline CS & $13(17.3 \%)$ & $36(8.8 \%)$ & I & I \\
\hline Spontaneous vaginal & $62(82.7 \%)$ & $373(91 \%)$ & $2.1729(|.09|-4.326)^{*}$ & $3.106(1.245-7.750)^{* *}$ \\
\hline \multicolumn{5}{|l|}{ Home to home education } \\
\hline Yes & $52(69.3 \%)$ & $77(18.8 \%)$ & I & I \\
\hline No & $23(30.7 \%)$ & $338(81.2 \%)$ & $9.778(5.642-16.944)^{*}$ & $5.4749(2.876-10.419)^{* *}$ \\
\hline \multicolumn{5}{|l|}{ Exposure to infant formula advertisement } \\
\hline Yes & $14(18.7 \%)$ & $283(69 \%)$ & $9.709(5.237-18.002)^{*}$ & $7.476(3.549-15.752)^{* *}$ \\
\hline No & $61(81.3 \%)$ & $122(31 \%)$ & 1 & 1 \\
\hline
\end{tabular}

Notes: *Stands for statistically significant at $p<0.05$ in bivariate analysis and **stands for statistically significant at $p<0.05$ in multivariate analysis.

were relatively old and multi-para. As a result, compared to younger mothers in this study, relatively elderly and multiparous mothers were more likely to provide prelacteal feeding. Moreover, older mothers are dominantly influenced by cultural experience and unable to change their behavior as opposed to young people.

In this finding, multipara mothers were almost four $(\mathrm{AOR}=3.56 ; \quad 95 \% \quad \mathrm{CI}=1.036-12.227) \quad$ and ten (AOR $=10.045 ; 95 \% \mathrm{CI}=1.456-19.289)$ times more likely than their counterparts to offer prelacteal feeding and colostrum avoidance. The study coincides with the three African countries in the regions of Burkina Faso, Uganda and South Africa ${ }^{31}$ and Tigray region, northern Ethiopia. ${ }^{19}$ This may be attributed to cultural resemblance. Multipara mothers are relatively older and are unable to learn about infant feeding and may have the potential to have an impact on cultural practices. This, in turn, contributes to the need for prelacteal feeding and colostrum avoidance of their infants.

The odds of colostrum avoidance among mothers who gave birth through spontaneous vaginal delivery were three times $(\mathrm{AOR}=3.106 ; 95 \% \mathrm{CI}=1.245-7.750)$, higher than, those mothers who gave birth via CS. This is contrary to a study conducted in Sudan. ${ }^{24}$ This difference could be due to the massive missed opportunity and less devotion of skilled attendants to provide essential newborn care, particularly early initiation of breastfeeding and counseling, since most of the mothers were delivered at the health institution via spontaneous vaginal birth. This means that institutional delivery is not a guarantee of optimal breastfeeding, but rather a high commitment of trained birth attendants delivering essential newborn care. 
Among mothers who do not have received home to home health education, the odds of colostrum avoidance were almost five times higher than their counterparts $(\mathrm{AOR}=5474 ; 95 \% \mathrm{CI}=2876-10,419)$. The study is consistent with the studies carried out in Aksum City and Raya Kobo District. ${ }^{11,28}$ This suggests that the provision of intensive health education on demerits of suboptimal breastfeeding can improve behavior and thereby enhance successful infant feeding practice.

The odds of colostrum avoidance among mothers who have exposure to infant formula advertisement were nearly seven times $(\mathrm{AOR}=7.476 ; 95 \% \mathrm{CI}=3.549-15.752)$, higher than their counterparts. The study is in line with report from South Sudan. ${ }^{32}$ This may be due to the fact that infant formula advertising has weakened breastfeeding and misled mothers to discard colostrum and to adopt prelacteal feed for their children. This suggests that the vigorous promotion of behavioral modification practices on colostrum feeding has gone undone.

\section{Strength and Limitation of the Study}

This study was community based with the maximum possible sample size inclusion upon which inference has been made. I have also used a standardized, expert reviewed and pretested data collection tool. Despite the fact that well-trained data collectors have been assigned, recall bias may be a concern among mothers with a child less than 12 months before the study to remember what happened to that child's feeding.

\section{Conclusion}

One in four infants is given early days of newborn feeding malpractice. This makes breastfeeding practices suboptimal in the city. Determinants of prelacteal feeding were found to be mothers who recognized the risk of prelacteal feeding, multipara mothers, having $\geq 4$ number of children and infant's birth order 4-6. Likewise, exposure to infant formula advertisement, absence of home-to-home health education, multipara mothers and spontaneous vaginal birth were the determinants of colostrum avoidance.

\section{Abbreviations}

AOR, adjusted odds ratio; ANC, antenatal care; CS, cesarian section; COR, crude odds ratio; UNICEF, United Nation International Children's Emergency Fund; WHO, World Health Organization.

\section{Data Sharing Statement}

All data generated or analyzed during this study are included in the manuscript and are also available from the corresponding author up on request.

\section{Ethical Approval and Consent to Participate}

The study protocol was evaluated and approved by Wollo University College of Medicine and Health Science with reference No_(WU/CMHS/345/2020) and Ethical clearance was obtained. Permission letters were also obtained from Mizan-Aman town health unit and respective kebeles. After giving a clear and deep understanding of the aim of the study, written consent was obtained from each respondent before the interview is conducted. In addition, prior to interviews with participants under 18 years of age, written informed consent was obtained from their parent or legal guardian. Any study participant found to be practicing suboptimal neonate feeding and to be less informed about optimal breastfeeding has been advised and referred to the under-five clinic for further assistance. Moreover, this study was conducted in compliance with the Declaration of Helsinki. Mothers who are unwilling were exempted from the study. Anonymous data were taken and the confidentiality of participant's information was secured.

\section{Acknowledgment}

The author would like to thank Mizan-Aman town health unit staff and community health workers for their kind cooperation. I am also thankful to data collectors and the study participants.

\section{Author Contributions}

The author made a significant contribution to conception and design, acquisition of data, or analysis and interpretation of data; took part in drafting, revising or critically reviewing the article; gave final approval of the version to be published; have agreed on the journal to which the article has been submitted; and agree to be accountable for all aspects of the work.

\section{Funding}

No external funds were obtained; only institutional support from Mizan-Aman health unit and Wollo University. 


\section{Disclosure}

The author declares that he has no competing interests in this work.

\section{References}

1. UNICEF. From the First Hour of Life: Making the Case for Improved Infant and Young Child Feeding Everywhere. New York: UNICEF; 2016.

2. World Health Organization. Baby-friendly hospital initiative: revised, updated and expanded for integrated care. 2009.

3. Victora CG, Bahl R, Barros AJ, et al. Breastfeeding in the 21st century: epidemiology, mechanisms, and lifelong effect. Lancet. 2016;387(10017):475-490. doi:10.1016/S0140-6736(15)01024-7

4. UNICEF, WHO. Capture the Moment-Early Initiation of Breastfeeding: The Best Start for Every Newborn. New York: UNICEF; 2018.

5. United Nations Inter-Agency Group for Child Mortality Estimation (UN IGME). Levels \& Trends in Child Mortality: Report 2019, Estimates Developed by the United Nations Inter-Agency Group for Child Mortality Estimation. New York: United Nations Children's Fund; 2019.

6. WHO. Indicators for assessing Infant and Young Child Feeding Practice Measurement. Conclusions of a consensus meeting held in Washington D.C., USA. 2010.

7. World Health Organization. Global Health Risks: Mortality and Burden of Disease Attributable to Selected Major Risks. World Health Organization; 2009.

8. Lakati A, Makokha O, Binns C, Kombe Y. The effect of pre-lacteal feeding on full breastfeeding in Nairobi, Kenya. East Afr J Public Health. 2011;7(3):258-262. doi:10.4314/eajph.v7i3.64737

9. McKenna KM, Shankar RT. The practice of prelacteal feeding to newborns among Hindu and Muslim families. J Midwifery Womens Health. 2009;54(1):78-81. doi:10.1016/j.jmwh.2008.07.012

10. Temesgen H, Negesse A, Woyraw W, Getaneh T, Yigizaw M. Prelacteal feeding and associated factors in Ethiopia: systematic review and meta-analysis. Int Breastfeed J. 2018;13(1):49. doi:10.11 86/s13006-018-0193-6

11. Weldesamuel GT, Atalay HT, Zemichael TM, et al. Colostrum avoidance and associated factors among mothers having children less than 2 years of age in Aksum town, Tigray, Ethiopia: a cross-sectional study 2017. BMC Res Notes. 2018;11(1):601. doi:10.1186/s13104018-3712-z

12. Gedamu H, Tsegaw A, Debebe E. The prevalence of traditional malpractice during pregnancy, child birth, and postnatal period among women of childbearing age in Meshenti town, 2016. Int J Reprod Med. 2018;2018:1-7. doi:10.1155/2018/5945060

13. The FANTA Project Academy for Educational Development. Ethiopian Profile analysis, 2005.

14. Hussien J, Assefa S, Liben ML. Breastfeeding performance in Afar regional state, northeastern Ethiopia: a cross sectional study. $B M C$ Pediatr. 2018;18(1):375. doi:10.1186/s12887-018-1353-y

15. Amele EA, Wondimeneh Demissie B, Desta KW, Woldemariam EB. Prelacteal feeding practice and its associated factors among mothers of children age less than 24 months old in Southern Ethiopia. Ital J Pediatr. 2019;45(1):1-8. doi:10.1186/s13052-019-0604-3

16. FMOH-E (Federal Ministry of Health Ethiopia). National Strategy for Infant and Young Child Feeding Ethiopia. 2004.

17. GotFDR E. National Nutrition Programme June 2013-June 2015. Addis Ababa: Government of Federal Democratic Republic of Ethiopia; 2013.
18. Csa I. Central Statistical Agency (CSA)[Ethiopia] and ICF. Addis Ababa, Ethiopia and Calverton, Maryland, USA: Ethiopia demographic and health survey; 2016.

19. Gebremeskel SG, Gebru TT, Kassahun SS, Gebrehiwot BG. Magnitude of prelacteal feeding and its associated factors among mothers having children less than one year of age: a community-based cross-sectional study in Rural Eastern Zone, Tigray, Ethiopia. Adv Public Health. 2020;2020:1-7. doi:10.1155/ 2020/4926890

20. Tariku A, Biks GA, Wassie MM, Gebeyehu A, Getie AA. Factors associated with prelacteal feeding in the rural population of northwest Ethiopia: a community cross-sectional study. Int Breastfeed J. 2016;11(1):14. doi:10.1186/s13006-016-0074-9

21. Nana C, Anteneh A. Prelacteal feeding and associated factors among newborns in rural Sidama, south Ethiopia. Int Breastfeed J. 2018;13(7).

22. Wolde TF, Ayele AD, Takele WW. Prelacteal feeding and associated factors among mothers having children less than 24 months of age, in Mettu district, Southwest Ethiopia. BMC Res Notes. 2019;12:9. doi:10.1186/s13104-019-4044-3

23. Argaw MD, Asfaw MM, Ayalew MB, et al. Factors associated with prelacteal feeding practices in Debre Berhan district, North Shoa, Central Ethiopia: a cross-sectional, community-based study. $B M C$ Nutr. 2019;5(1):14. doi:10.1186/s40795-019-0277-8

24. Tongun JB, Sebit MB, Ndeezi G, Mukunya D, Tylleskar T, Tumwine JK. Prevalence and determinants of pre-lacteal feeding in South Sudan: a community-based survey. Glob Health Action. 2018;11(1):1523304. doi:10.1080/16549716.2018.1523304

25. Nguyen PH, Keithly SC, Nguyen NT, Nguyen TT, Tran LM, Hajeebhoy N. Prelacteal feeding practices in Vietnam: challenges and associated factors. BMC Public Health. 2013;13(1):932. doi:10.1186/1471-2458-13-932

26. Abdel-Hady D, El-Gilany AH, Sarraf B. Dietary habits of adolescent students in Mansoura, Egypt. Int $J$ Collab Res Intern Med Public Health. 2014;6(6):132.

27. Bekele Y, Mengistie B, Mesfine F. Prelacteal feeding practice and associated factors among mothers attending immunization clinic in Harari region public health facilities, Eastern Ethiopia. Open J Prev Med. 2014;2014.

28. Legesse M, Demena M, Mesfin F, Haile D. Factors associated with colostrum avoidance among mothers of children aged less than 24 months in Raya Kobo district, North-eastern Ethiopia: community-based cross-sectional study. J Trop Pediatr. 2015;61 (5):357-363. doi:10.1093/tropej/fmv039

29. Gebreyesus H, Girma E, Cherie N. Colostrum avoidance and associated factors among mothers of children aged less than 12 months in Kombolcha town, South Wollo zone, Ethiopia. Medrech. 2017;4 (05):545-559.

30. Khanal V, Adhikari M, Sauer K, Zhao Y. Factors associated with the introduction of prelacteal feeds in Nepal: findings from the Nepal demographic and health survey 2011. Int Breastfeed J. 2013;8(1):9. doi:10.1186/1746-4358-8-9

31. Engebretsen IM, Nankabirwa V, Doherty T, et al. Early infant feeding practices in three African countries: the PROMISE-EBF trial promoting exclusive breastfeeding by peer counsellors. Int Breastfeed $J$. 2014;9(1):19. doi:10.1186/1746-4358-9-19

32. Tongun JB, Sebit MB, Mukunya D, et al. Factors associated with delayed initiation of breastfeeding: a cross-sectional study in South Sudan. Int Breastfeed J. 2018;13(1):28. doi:10.1186/s13006-0180170-0 


\section{Publish your work in this journal}

Pediatric Health, Medicine and Therapeutics is an international, peerreviewed, open access journal publishing original research, reports, editorials, reviews and commentaries. All aspects of health maintenance, preventative measures and disease treatment interventions are addressed within the journal. Practitioners from all disciplines are invited to submit their work as well as healthcare researchers and patient support groups. The manuscript management system is completely online and includes a very quick and fair peer-review system. Visit http://www.dovepress.com/testimonials.php to read real quotes from published authors.

Submit your manuscript here: http://www.dovepress.com/pediatric-health-medicine-and-therapeutics-journal 